\title{
The Effects of the Trade Winds on the Distribution of Relative Humidity and the Diurnal Air Temperature Cycle on Oceanic Tropical Islands
}

\author{
Ronalds $\mathrm{RT}^{1}$, Emiliano $\mathrm{A}^{1}$ and Rafael Mendez-Tejeda ${ }^{2 *}$
}

${ }^{1}$ School of Natural Science and Technology, Universidad del Turabo, Gurabo, PR, USA

${ }^{2}$ Atmospheric Sciences Laboratory, University of Puerto Rico at Carolina, PO Box 4800, Carolina, PR, USA

\begin{abstract}
On many oceanic tropical islands the trade winds blow from the east and as the air passes over the island it loses moisture to rain. The two hypotheses for this study are that the western part of the island is less humid and has a larger diurnal air temperature cycle. Using data available on the Internet, the two hypotheses were assayed 7 times on 6 different islands in the Pacific and Caribbean. The islands used in this study are Puerto Rico, Hispaniola, the Big Island of Hawaii, Maui, Oahu, and Kauai. The first hypothesis was tested only on Hispaniola and is true. The second hypothesis was tested on all the islands and is true on all the islands except on the Big Island of Hawaii and Maui. Using a p-value of 0.05 , these hypotheses are as predicted 5 of the 7 times, which has a $p$-value of $6 \times 10^{-6}$. These findings should apply to thousands oceanic tropical islands where data are sparse.
\end{abstract}

Keywords: Rain shadow; Oceanic tropical Islands; Trade winds

\section{Introduction}

The Earth has an estimated 45,000 tropical islands larger than $0.05 \mathrm{~km}^{2}$ (5 hectares) [1]. The populations of these islands range from zero to 143 million on the Indonesian island of Java. Oceanic tropical islands often have environmental problems that include high population densities, water scarcity, and extinctions [2]. Data are often sparse [1], but because inputs and processes are similar, many oceanic tropical islands have commonalities including climate and in general vegetation. This study will look for patterns on data-rich islands. Nothing in this study will prove that these patterns apply to data-sparse islands but it will generate hypotheses that can help guide future research on other oceanic tropical islands.

This study has two parts. First a simple theoretical approach, that examines how on many oceanic tropical islands, the easterly trade winds shape the distribution of the two variables of this study. And second, searching for available data to test the hypotheses generated from the theoretical approach. This is a pilot study. The vast majority of oceanic tropical islands do not have any available data to verify these hypotheses.

Over the open water, upwind of an oceanic tropical island the relative humidity is typically around 80 percent [3]. The average value of relative humidity is an equilibrium between evaporation which, on a daily basis, is almost constant and frequent but light rain storms that remove moisture out of the air. As a parcel of air moves over land it is disconnected from its source of moisture and from upwind to downwind it loses moisture to rainfall and becomes drier. When the winds are consistent, the interaction between the wind and the land creates a region with a reduced water vapor concentration in the atmosphere. The western part of the island is in the rain shadow of eastern end of the island. This structure in the atmosphere is a permanent feature even as the air in it is being constantly replaced. The exact patterns of climate will be affected by many factors including topography, the shape of the coastline, distance from the coast, and anthropogenic factors such as urban heat islands. The existence of this area of reduced water vapor content can be predicted solely on the basis of longitude and is independent of the specifics of the other factors. The distance from the eastern tip of the island can be measured either in degrees of longitude or kilometers and it would not change the results. The rates of rainfall and runoff are typically much higher in the humid tropics than in temperate regions [4] and the higher rainfall will increase the contrast between upwind and downwind areas.

There are at least three methods to study the interaction between the prevailing trade winds and the land mass. Large numbers of temporary instruments can be deployed to provide a large amount of data over the span of a few weeks. Such an experiment is described for the Big Island of Hawaii by Chen and Nash [5]. A second approach is to use digital elevation models, complex mathematical algorithms, and expert knowledge to generate detailed maps of climate variables and this is the approach used in the Parameter-elevations Regression on Independent Slope Model (PRISM) [6]. The application of PRISM to the island of Puerto Rico is in Daly et al. [7]. A third approach is used in this study. This study looks at data-rich islands and uses simplified mathematical relationships to look for generalized patterns that probably exist on thousands of oceanic tropical islands where data are sparse. The simplified relationship will require less data than more complex patterns.

On many oceanic tropical islands the trade winds consistently blow from the east. This has been documented for Hawaii [5], Hispaniola [8] and Puerto Rico [9]. The eastern two-thirds of Hispaniola is the Dominican Republic while the western one-third is Haiti. In Puerto Rico, the wind blows between northeast and southeast at least 65 percent of the time [10]. A detailed study of the trade winds in Hawaii is in Giambelluca and Nullet [11]. Data-rich islands have studies but there are few studies that compare the environments of widely separated islands.

The structure of the atmosphere in the Caribbean is important

*Corresponding author: Rafael Mendez-Tejeda, Atmospheric Sciences Laboratory, University of Puerto Rico at Carolina, Carolina, PR, USA 00984, Tel: 787-257-0000 x4715; E-mail: rafael.mendez@upr.edu

Received July 10, 2015; Accepted July 25, 2015; Published August 03, 2015

Citation: Ronalds RT, Emiliano A, Méndez-Tejeda R (2015) The Effects of the Trade Winds on the Distribution of Relative Humidity and the Diurnal Air Temperature Cycle on Oceanic Tropical Islands. J Climatol Weather Forecasting 3: 137. doi:10.4172/2332-2594.1000137

Copyright: (c) 2015 Mendez-Tejeda R, et al. This is an open-access article distributed under the terms of the Creative Commons Attribution License, which permits unrestricted use, distribution, and reproduction in any medium, provided the original author and source are credited. 
locally for the islands and is connected to continental scale patterns. The North Atlantic Oscillation (NAO) is derived from the difference in barometric pressure between Iceland and Portugal. High levels of the NAO index are associated with high precipitation in northern Europe and low precipitation in southern Europe and Puerto Rico [12]. In late summer in the northern Antilles rainfall is associated with a negative NAO index combined with warm conditions in the El Niño Southern Oscillation in the eastern Pacific Ocean [13]. The Caribbean Low Level Jet (CLLJ) transports moisture to Central America and the eastern part of North America. Variability in the CLLJ is associated with variability of precipitation in the downwind areas [14]. Several studies have analyzed the inter-annual variability of Caribbean rainfall [15-18]. The climatological mean, annual, and monthly rainfall in Haiti is a complex function of fixed factors including the topography and shape of the country, as well as the annual cycle of regional-scale oceanic and atmospheric factors. The atmosphere is in the northern Antilles is dominated by the permanent Azores high, which induces permanent easterlies across the Caribbean islands [19].

The variables in this study are affected by multiple factors such as elevation, distance from coast, the shape of mountain ranges, and anthropogenic factors such as urban heat islands. The central question of this study is if longitude is needed to be added to the list to explain the observed data. The basic idea is that the consistency of the trade winds creates a rain shadow in the western parts of oceanic tropical islands. Mountains in Puerto Rico create a rain shadow [7]. At 3098 m, Pico Duarte is the highest mountain in Hispaniola and the Caribbean. The rain shadow of this mountain affects the climate of Jamaica and eastern Cuba [20]. Data are extremely limited for most oceanic tropical islands and this study will use simple patterns with limited data requirements to see if the results are useful and can then be extended to other islands.

The trade winds blow from the east and the air loses water to rain as it passes over the land. This concept generated two hypotheses. The second hypothesis derives from the first. In numerical form, the hypotheses will be stated for the western hemisphere; in the eastern hemisphere the correlations are reversed. Each hypothesis will be stated as a correlation with longitude. Longitude has an arbitrary datum in Greenwich, United Kingdom but it would not affect the correlations of this study if the datum were the eastern tip of the island or any other location. The hypotheses, for oceanic tropical islands, are:
First: the western part of the island is in the rain shadow of the east and there will be an inverse correlation between longitude and relative humidity.

Second: the diurnal air temperature cycle is the average difference between the daily highs and the lows at night and will be correlated with longitude. Dry air is more transmissive of infrared radiation [21], and with the same amount of solar radiation, the days will be hotter and the nights will be colder, as occurs in deserts [22]. There is a published map of the diurnal air temperature cycle in Puerto Rico [10]. The correlation with longitude is visible on the map but the interpretation is based on distance from the coast.

The vast majority of the oceanic tropical islands on Earth have no data to assay these hypotheses. There are other islands that have data but they are not readily available. This study uses data collected by government meteorological agencies and made available on the Internet. At least one hypothesis was tested on 6 islands. The two Caribbean islands in this study are Hispaniola and Puerto Rico. All data from Hispaniola are from the Dominican Republic as no data are available for the Haitian side of the island. The Hawaiian Islands used in this study are the Big Island of Hawaii, Maui, Oahu, and Kauai. Puerto Rico and Hawaii are part of the United States.

The 6 islands in this study are not representative of the 45,000 tropical islands on Earth. All are in the northern hemisphere and all are in the western hemisphere. All are near the Tropic of Cancer and none are in the deep tropics. None of the islands are in the Indian Ocean. The largest concentration of tropical islands on Earth is between Asia and Australia and none of the islands in this study are in this part of the world. These are the islands for which data are available on the Internet and if the hypotheses work on these islands it can guide the work of future researchers on other islands. The islands of this study are well separated from continental landmasses. Future work will be needed to understand the relationship between distance and the effect of continents on the climate of tropical islands. The large masses of ocean water around the islands of this study buffers the climate and reduces the annual air temperature cycle.

The location of the islands are in Figure 1. The data were collected by the National Weather Service (NWS), except in the Dominican Republic where they were collected by the Oficina Nacional de

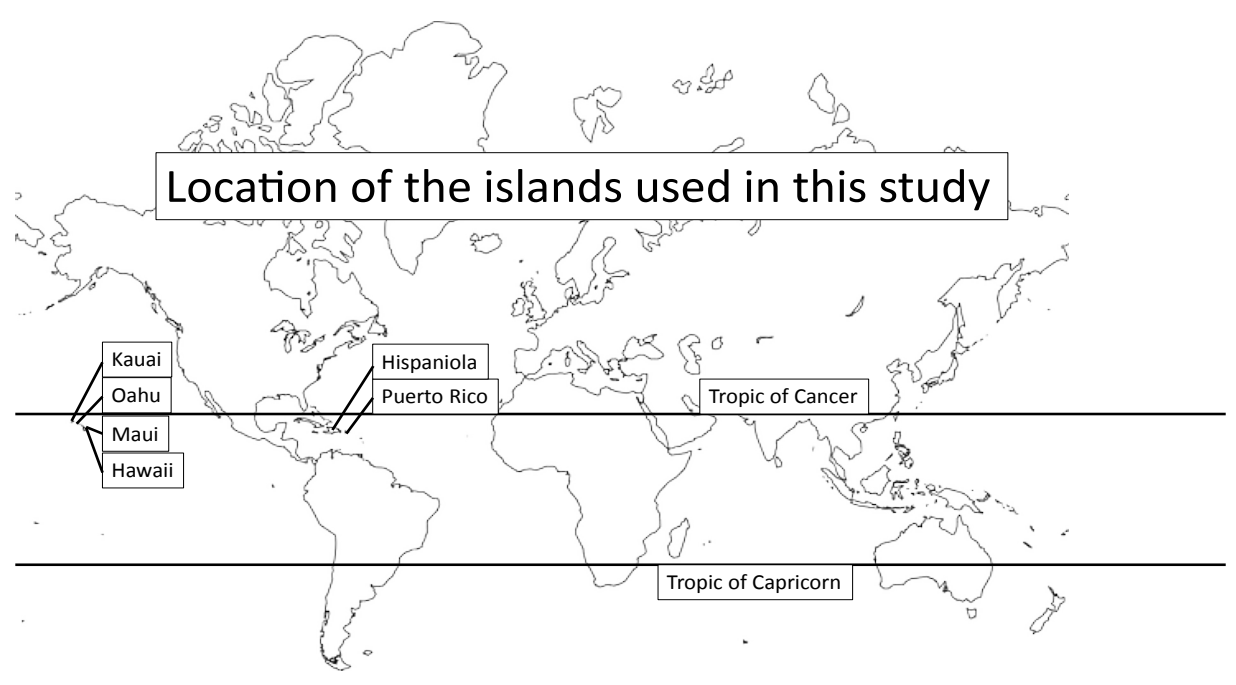

Figure 1: Locations of the oceanic tropical islands used in this study. 
Meteorología (ONAMET). NWS data are at the Southeast Regional Climate Center [23] and the Western Regional Climate Center [24]. The data from the Dominican Republic are at World Climate [25] and were submitted to the World Meteorological Organization and edited by the National Climate Data Center (NCDC). Both the NWS and the NCDC are part of the National Oceanic and Atmospheric Administration of the United States.

\section{Material and Methods}

The hypotheses were tested for every oceanic tropical island for which data could be found on the Internet. Typically for each station the metadata includes latitude, longitude, and elevation. For each hypothesis assayed, each island has between 15 and 68 data points. The data were plotted versus longitude and visually examined for outliers, which were excluded. The Pearson correlation coefficient was calculated, the p-value used was 0.05 .

The hypotheses were assayed with climate stations that had at least 7 years of data and in many cases 30 or more years. The first hypothesis, which states that the western ends of oceanic tropical islands have lower relative humidity than the eastern parts, was assayed only for the island of Hispaniola. The data were the monthly average relative humidity, which were averaged to produce the average relative humidity. The second hypothesis, stating that the diurnal air temperature cycle is larger in the western parts of the islands was assayed for all of the islands. The monthly air temperature cycle is the average high temperature in a month less the average low temperature in the month. In the tropics, the diurnal air temperature cycle is 65 percent of the monthly cycle [26], so the monthly average high and low temperature was used as a proxy for the diurnal cycle. A proxy was needed because data on the diurnal air temperature cycle are not readily available. Each station has a value for the monthly difference between high and low temperature and these were averaged to produce a single value for the station over the course of a year.

The hypotheses were also assayed for north-south differences. If the trade winds are converging on the equator then it would be logical that the low latitude part of the island would be dryer and have a larger diurnal air temperature cycle.

\section{Results}

The results are in Table 1. The graph of average relative humidity versus longitude for Hispaniola is shown in Figure 2. There are 15 data points. The 13 data points from stations below $200 \mathrm{~m}$ above sea level showed a clear trend from 83 to 63 percent relative humidity. The two stations higher than $400 \mathrm{~m}$ above sea level were more humid and were excluded as outliers. The Pearson correlation coefficient was -0.74 which had a p-value of 0.0019 .
Hypothesis number two predicts that the western parts of oceanic tropical islands will have a larger diurnal air temperature cycle and this was tested with monthly air temperature data. The average monthly air temperature cycles for Hispaniola and Puerto Rico are shown in Figure 3, while Figure 4 has the same data for the four Hawaiian Islands. All six islands had a larger diurnal temperature cycle in the western parts of the islands but the correlations were not significant in the Big Island of Hawaii and Maui.

The hypotheses of this study were assayed 7 times on 6 oceanic tropical islands in two groups in two oceans. The hypotheses were as predicted 5 of the 7 times. The binomial distribution was used to calculate the $\mathrm{p}$-value for this to occur by random chance and the result is 6 times in a million trials. The testing of the north-south hypotheses produced no significant results.

\section{Discussion}

The correlations in this study are based on the consistency of the easterly trade winds. In parts of south Asia and the island-rich region between Asia and Australia, the climate is dominated by the monsoon pattern which can include abrupt changes in wind direction and precipitation [27]. Understanding how the Asia monsoon affects the climatology of tropical islands is crucial in the extension of this study to other areas such as Indonesia and the Philippines; however none of the islands in this study are affected by the monsoon pattern.

In Maui the hypothesis on the correlation between longitude and the monthly air temperature cycle has 20 data points, a Pearson correlation coefficient of 0.37 , and a p-value of 0.054 . It was classified as insignificant but it is right on the edge and with one more station the correlation would be significant. The Big Island of Hawaii is a different story. With 37 data points, the Pearson correlation coefficient is 0.091 , and the $p$-value is 0.29 . To be significant a Pearson correlation coefficient of 0.1 requires more than 250 data points.

The largest and most populated island used in this study is Hispaniola, which has an area of $76,500 \mathrm{~km}^{2}$, a maximum elevation of $3098 \mathrm{~m}$ above sea level, and a population of over 20 million people, split almost evenly between the Dominican Republic and Haiti. The population density of Hispaniola is 259 people per square kilometer. Kauai is the smallest and least populated island in this study. Kauai has an area of $1430 \mathrm{~km}^{2}$, a maximum elevation of $1598 \mathrm{~m}$ above sea level, a population of 67,000 , and a population density of 47 people per square kilometer. Oahu is the lowest and most densely populated island in the study. Oahu has an area of $1545 \mathrm{~km}^{2}$, an elevation of 1220 $\mathrm{m}$, a population of 953,000 , and a population density of 617 people per square kilometer. The Big Island of Hawaii is the highest in elevation and has the lowest population density. The Big Island of Hawaii has an area of $10,432 \mathrm{~km}^{2}$, an elevation of $4205 \mathrm{~m}$, and a population of 185,000 with a population density of 18 people per square kilometer.

\begin{tabular}{|c|c|c|c|c|c|c|c|c|c|c|}
\hline \multicolumn{6}{|c|}{ Relative humidity } & \multicolumn{5}{|c|}{ Diurnal air temperature cycle } \\
\hline \multicolumn{6}{|c|}{ Hypothesis \#1 } & \multicolumn{5}{|c|}{ Hypothesis \#2 } \\
\hline Island & $\mathrm{m}^{\mathrm{a}}$ & $\mathrm{b}^{\mathrm{b}}$ & $r^{c}$ & $n^{d}$ & $\mathrm{p}$-value & $\mathrm{m}$ & $b$ & $r$ & $\mathrm{n}$ & $\mathrm{p}$-value \\
\hline Puerto Rico & e & & & & & 2.47 & -154 & 0.54 & 44 & $<0.001$ \\
\hline Hispaniola & -4.05 & 362 & -0.74 & 13 & 0.0019 & 1 & -60 & 0.52 & 68 & $<0.001$ \\
\hline Hawaii & & & & & & $0.379^{f}$ & -50 & 0.091 & 37 & 0.29 \\
\hline Maui & & & & & & 287 & -439 & 0.37 & 20 & 0.054 \\
\hline Oahu & & & & & & 7.23 & -1130 & 0.65 & 30 & $<0.001$ \\
\hline Kauai & & & & & & 9.01 & -1430 & 0.9 & 16 & $<0.001$ \\
\hline
\end{tabular}

${ }^{a} \mathrm{~m}$ is slope; ${ }^{b} \mathrm{~b}$ is intercept; ${ }^{c} \mathrm{r}$ is Pearson correlation coefficient; ${ }^{\mathrm{d}} \mathrm{n}$ is sample size; eblank cells represent no data; fhighlighted in gray are insignificant

Table 1: Results of assaying the hypotheses on oceanic tropical Islands. 


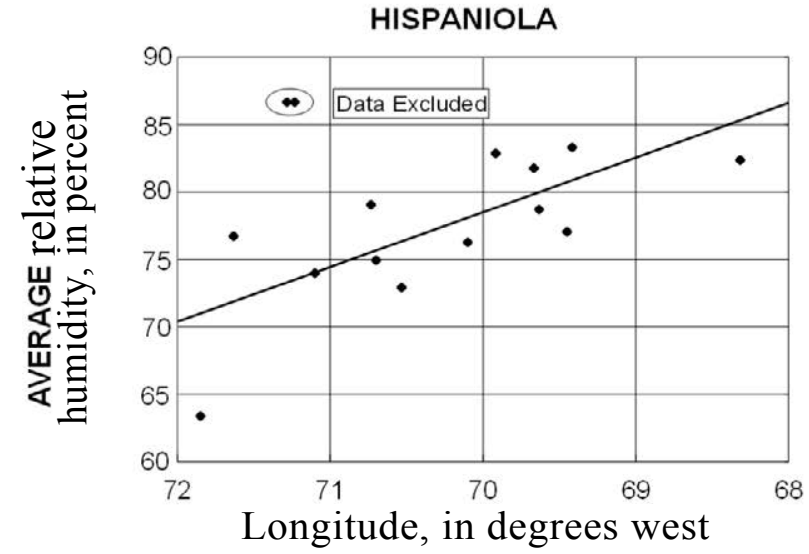

Figure 2: Hypothesis \#1- Average Relative Humidity Versus Longitude for Hispaniola. The excluded data are from stations over $400 \mathrm{~m}$ in elevation while the rest of the data are from stations within $200 \mathrm{~m}$ of sea level. Data modified from World Climate.

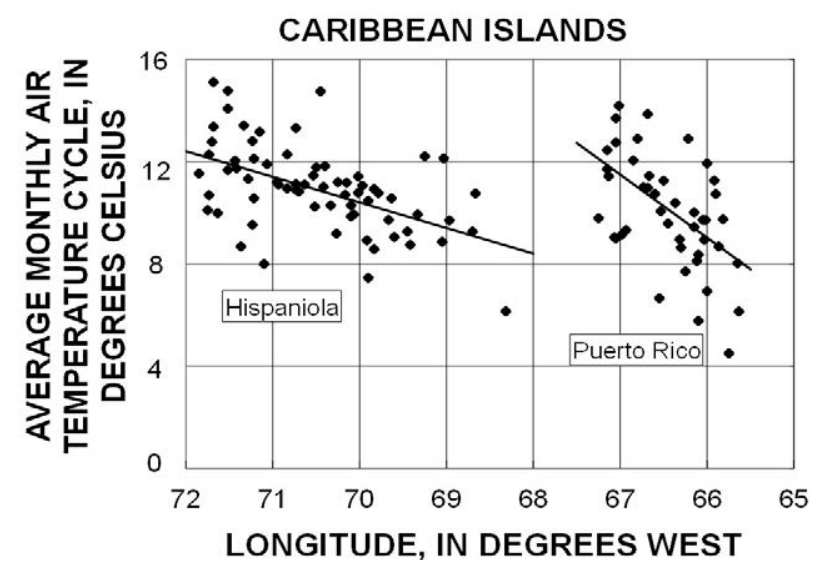

Figure 3: Average monthly air temperature cycle versus longitude for Hispaniola and Puert Rico. Data modified from World Climate and Southeast Regional Climate Center.

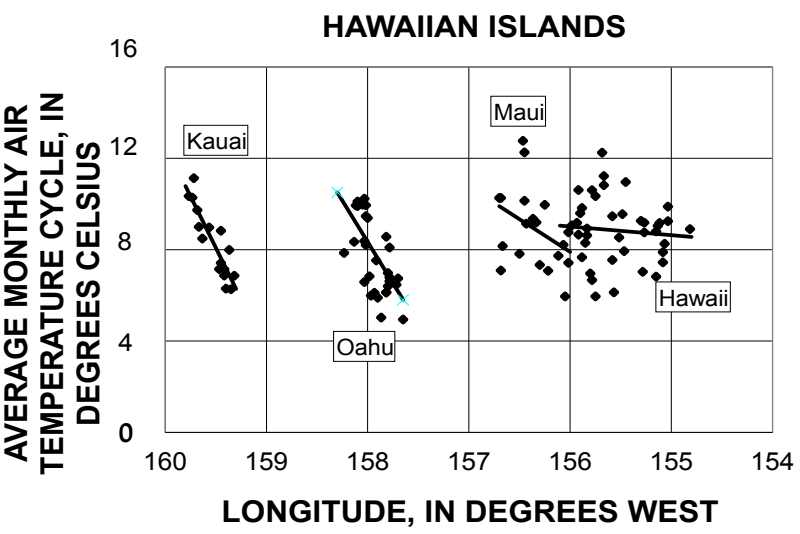

Figure 4: Hypothesis \#2--Average monthly air temperature cycle versus longitude for four Hawaiian Islands. The monthly air temperature cycle is a proxy for the diurnal air temperature cycle. Dashed lines are used when the correlation is not significant. The Big Island of Hawaii and Maui slightly overlap in longitude. Data modified from Western Regional Climate Center.
The wind blows from the east, and as the air mass moves over land from east to west it loses moisture to rain and becomes drier. The pattern is simplistic but it produced two hypotheses which could be tested with data that are publically available on the Internet. The hypotheses were successful in predicting observations on widely separated oceanic tropical islands. The variables used in this study are affected by multiple factors like elevation, proximity to the coast, the shape of mountains, and anthropogenic factors like urban heat islands, the consistency of the easterly trade winds adds longitude to the list. A simple correlation with limited data requirements produced useful results even though the distance between Puerto Rico and Hawaii is more than $9,000 \mathrm{~km}$.

Oceanic tropical islands are tiny specks of land spread out over vast distances of ocean. On thousands of these islands, the easterly trade winds shape the environment in predictable ways. This study is the first part of a larger effort to identify these underlying physical processes that can help improve the management of water and other natural resources on these islands. The easterly trade winds affects not only the humidity and diurnal air temperature cycle but probably also the temperatures of sea surface, rivers, and groundwater. These abiotic conditions shape the environment for plants, animals, bacteria and fungi. Puerto Rico is a good place to start because its political relationship with the United States has made it one of the most data-rich places on Earth. The goal is science that can improve the management of water and other natural resources in Puerto Rico while at the same time providing insights that can help in the environmental management of thousands of islands where data are sparse. Puerto Rico is and island but the viewpoint should not be insular but rather one that is inclusive of the tens of thousands oceanic tropical islands with similar climates and environmental problems.

\section{Conclusion}

The consistency of the easterly trade winds on oceanic tropical islands leads to two predictions which can be assayed with data that are publically available on the Internet. The hypotheses that were verified on two islands in the Caribbean and four in the Pacific are that on the western end of the island the relative humidity is lower and the diurnal air temperature cycle is larger. These patterns probably exist on thousands of islands for which there are no readily available data. With more data it should be possible to observe these patterns much more widely.

It has been observed that on islands, the topography of the island can act as an obstacle or barrier to the wind causing an unequal distribution of humidity and diurnal air temperature cycle. This study establishes the difference between the east (windward) and the west (leeward) part of the islands. The east side benefit from the moisture of the trade winds, while the west slope receives dryer wind. This generates microclimates that also depend on elevation and large differences can occur across small horizontal distances.

\section{Acknowledgements}

This study was possible because of the effort of observers and employees of different agencies who for more than 50 years have collected, processed, and archived the data used in this study. Their names are unknown, but their work is appreciated.

\section{References}

1. Arnberger $\mathrm{H}$, Arnberger $\mathrm{E}$ (2001) The tropical islands of the Indian and Pacific Oceans. Austrian Academy of Sciences. Vienna pp. 556.

2. Olson SL, James HF (1984) The role of Polynesians in the extinction of the 
Citation: Ronalds RT, Emiliano A, Méndez-Tejeda R (2015) The Effects of the Trade Winds on the Distribution of Relative Humidity and the Diurnal Air Temperature Cycle on Oceanic Tropical Islands. J Climatol Weather Forecasting 3: 137. doi:10.4172/2332-2594.1000137

Page 5 of 5

avifauna of the Hawaiian Islands. In: Quaternary Extinctions: A prehistoric revolution, The University of Arizona Press, Tucson pp. 760-780.

3. Emanuel KA (1987) The dependence of hurricane intensity on climate. Nature 326: 483-485.

4. Bonell M, Hufschmidt MM, Gladwell JS (2005) Hydrology and Water Management in the Humid Tropics: Hydrological Research.

5. Chen YL, Nash AJ (1994) Diurnal variation of surface airflow and rainfal frequencies on the island of Hawaii. Monthly Weather Review 122: 34-56.

6. Daly C, Gibson WP, Taylor GH, Johnson GL, Pasteris P (2002) A knowledgebased approach to the statistical mapping of climate. Climate Research 22: 99103

7. Daly C, Helmer EH, Quiñones M (2003) Mapping the climate of Puerto Rico, Vieques and Culebra. International Journal of Climatology 23: 1359-1381.

8. Izzo M, Rosskopf CM, Aucelli PPC, Maratea A, Méndez R, et al. (2010) A new climatic map of the Dominican Republic based on the Thornthwaite classification. Physical Geography 31: 455-472.

9. Carter MM, Elsner JB (1996) Collective rainfall regions of Puerto Rico. International Journal of Climatology 16: 1033-1043.

10. Colón Torres JA (2009) Weather In Puerto Rico. Editorial University of Puerto Rico. San Juan.

11. Giambelluca TW, Nullet D (1991) Influence of the trade-wind inversion on the climate of a leeward mountain slope in Hawaii. Climate Research 1: 207-216.

12. Malmgren BA, Winter A, Chen D (1998) El Niño-Southern Oscillation and North Atlantic Oscillation control of climate in Puerto Rico. Journal of Climate 11: 2713-2717.

13. Gouirand I, Jury MR, Sing B (2012) An analysis of low- and high frequency summer climate variability around the Caribbean Antilles. Journal of Climate 25: 3942-3952.

14. Wang C (2007) Variability of the Caribbean Low-Level Jet and its Relations to Climate. Climate Dynamics 29: 411-422.
15. Enfield DB, Alfaro EJ (1999) The dependence of Caribbean rainfall on the interaction of the tropical Atlantic and Pacific Oceans. Journal of Climate 12 2093-2103.

16. Giannini A, Kushnir Y, Cane MA (2000) Interannual variability of Caribbean rainfall, ENSO, and the Atlantic Ocean. Journal of Climate 13: 297-311.

17. Giannini A, Chiang JCH, Cane MA, Kushnir Y, Seager R (2001) The ENSO teleconnection to the tropical Atlantic Ocean: Contribution of the remote and local SSTs to rainfall variability in the tropical Americas. Journal of Climate 14 4530-4544.

18. Taylor MA, Enfield DB, Chen AA (2002) Influence of the tropical Atlantic versus the Tropical Pacific on Caribbean rainfall. Journal of Geophysical Research 107: $10-14$.

19. Moron V, Frelat, R, Jean-Jeune PK, Gaucherel C (2014) Interannual and intraannual variability of rainfall in Haiti. Climate Dynamics 45: 915-932.

20. Jury MR (2009) An intercomparison of observational, reanalysis, satellite and coupled model data on mean rainfall in the Caribbean, Journal of Hydrometeorology 19: 413-430.

21. Pierrehumbert RT (2011) Infrared Radiation and Planetary Temperature. Physics Today 64: 33-38.

22. McGregor GR, Nieuwolt S (1998) Tropical climatology: an introduction to the climate of the low latitudes. John Wiley and Sons, Hoboken, pp. 339.

23. Southeast Regional Climate Center (2014). http://www.sercc.com

24. Western Regional Climate Center (2014). http://www.wrcc.com

25. World Climate (2014). http://www.climate-charts.com

26. Watterson IG (1997) The diurnal cycle of surface air temperature in simulated present and doubled CO2 climates. Climate Dynamics 13: 533-545

27. Chang C-P, Wang Z, McBride J, Liu CH (2005) Annual cycle of Southeas Asia -Maritime Continent rainfall and the asymmetric monsoon transition Institutional Archive of the Naval Postgraduate School, J Climate 18: 287-301.
Citation: Ronalds RT, Emiliano A, Méndez-Tejeda R (2015) The Effects of the Trade Winds on the Distribution of Relative Humidity and the Diurnal Air Temperature Cycle on Oceanic Tropical Islands. J Climatol Weather Forecasting 3: 137. doi:10.4172/2332-2594.1000137 